\title{
Construction techniques for bored piling in sand using polymer fluids
}

1 Carlos Lam DPhil, CEng, MICE, MHKIE Lecturer in Geotechnical Engineering, School of Mechanical, Aerospace and Civil Engineering, The University of Manchester, Manchester, UK
2 Stephan A. Jefferis PhD, CEng, CEnv, CGeol, FICE, FGS Director, Environmental Geotechnics Ltd, Adderbury, Banbury, UK Visiting Professor, Department of Engineering Science, University of Oxford, UK

3 Tony P. Suckling MSC, CEng, FICE Technical Director, Balfour Beatty Ground Engineering, Basingstoke, UK

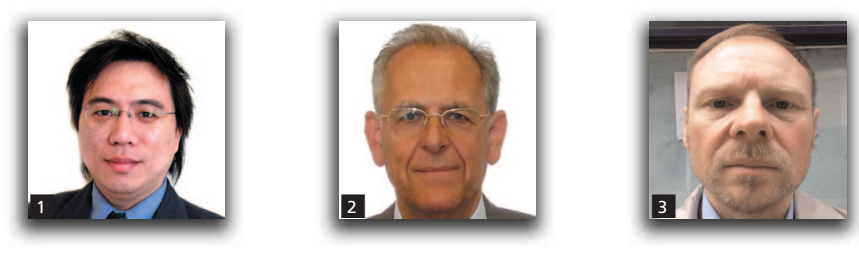

This paper is concerned with the use of polymer fluids for the construction of bored piles in silty fine sand, a situation which has been found to significantly increase the risk of 'soft toes' and concrete contamination due to the settling of the suspended soil particles in the fluid. To illustrate how these problems can be avoided by adopting a simple fluid-testing regime and improved construction practice, this paper presents a case history of polymer use at a site in Glasgow where the ground conditions consist of silty fine sand. Fluid testing showed that the used polymer fluid was heavily laden with soil particles and that cleaning using chemical additives alone was not sufficient to reduce the amount of suspended solids to an acceptable level. The pile bores were therefore left open overnight to allow the particles to settle out of suspension, the effect of which was confirmed by further fluid testing. The settled solids were removed with a base cleaning bucket. Structural integrity tests conducted on over 50 working piles constructed using this method showed no sign of defects. High-strain dynamic loading tests on two completed piles also confirmed their performance despite the extended pile bore open period.

\section{Notation}

$C_{\mathrm{U}} \quad$ coefficient of uniformity

$C_{Z} \quad$ coefficient of curvature

$D_{x} \quad$ particle size for which $x \%$ of the sample is finer

$s \quad$ sediment thickness

$t \quad$ time after excavation

\section{Introduction}

Synthetic polymer fluids have been used for the construction of bored piles in the UK since the 1990s. These fluids have physical and chemical properties distinct from the better known bentonite slurries. Therefore, the use of polymer fluids requires careful adaptation of existing construction techniques and an understanding of the effects of these fluids on the completed foundation elements. Over the past decade, considerable experience has been gained in terms of these issues and the strengths and weaknesses of polymer fluids are now much better known. For example, Anonymous (2001), Wheeler (2003) and Lennon et al. (2006) reported that the use of polymer fluids can offer significant operational benefits including smaller site footprints, shorter plant (de)mobilisation time, drier excavated materials and lower fluid disposal costs. Schünmann (2004) added that polymer fluids can be used in environmentally sensitive areas such as river sides, as any spilled fluids will not build up on the gills of fish and cause suffocation. More recently, Lam et al. (2010a, 2014a) reported that polymer fluids can lead to higher pile shaft resistance compared to bentonite, and that a pile bore open time of up to $26 \mathrm{~h}$ does not appear to reduce the performance of piles constructed using polymers.

Notwithstanding the benefits, the use of polymer also brings new challenges. For example, the viscosity of the fluid can be significantly reduced by the use of unsuitable pumping equipment and by contaminants in the ground (Jefferis and Lam, 2013; Lam et al., 2010b). Uncontrolled reuse of the fluid can lead to depletion of the active polymers (Lam et al., 2014b). Previous experience has also shown that the use of these fluids can increase the risk of 'soft toe' and concrete contamination due to the settling of suspended soil particles (Brown, 2004; Fleming et al., 2009). Unlike a gelling bentonite slurry which may perhaps 
suspend soil particles up to coarse sand size, polymer fluids have a lower particle-holding ability owing to their different rheological properties. Under typical polymer fluid conditions, particles smaller than coarse silt will tend to remain in suspension as their settling rate will be too low for them to reach the base of the excavation in significant quantities. Coarser particles of sand size, although settling faster, will continue to accumulate at the base of a pile for a significant time depending on the height of the polymer column through which they must settle (i.e. the depth of the pile). The potential problems of 'soft toe' and concrete contamination are therefore the most significant for ground conditions consisting mainly of coarse silts and sands, as these are the particle sizes that are most likely to settle out of suspension after the completion of an excavation and prior to concreting. Brown (2004) reported that there have been numerous cases of projects with polymer fluids where removal of silts and fine sands from the fluid has been difficult. On one project near the Atlantic coast in the USA, the contractor had to overpour the concrete by over $2 \mathrm{~m}$ in order to remove concrete contaminated with silt. On another project in Florida in silty fine sands, the bases of the pile bores were inspected using a down-hole camera which revealed the bottom $0.6 \mathrm{~m}$ of fluid to be heavily laden with silt so that it appeared as a gel. Based on these and other anecdotal experiences with polymer fluids in silty fine sands, Brown (2004) urges engineers and contractors to exercise caution in the use of polymers in these ground conditions. The authors agree that care is necessary and this paper sets out the basic issues. However, it must also be mentioned that, despite these American experiences, polymer fluids have also been used very successfully in projects with similar ground conditions in Glasgow, Scotland since the late 1990s (Lennon et al., 2006) as a result of the employment of improved construction techniques.

To illustrate how the potential issues of 'soft toes' and concrete contamination can be avoided by following a simple yet effective fluid-testing regime and adjustment to the construction techniques, this paper presents a case history of polymer use for a bored piling project in Glasgow. In the following sections, various aspects of the project are discussed, including site conditions, construction details, structural integrity tests and dynamic loading tests.

\section{Site and ground conditions}

The site was located about $500 \mathrm{~m}$ north-west of the Argyle Street station and about the same distance north of the River Clyde in central Glasgow. Typical of that area, the ground conditions consist of a layer of made ground underlain by a thick layer of alluvial silty fine sand and then bedrock consisting of bands of mudstone, siltstone and sandstone. Thin layers of coal (lignite) are also commonly found above the bedrock in the area. Table 1 summarises the depths and engineering descriptions of the soil layers encountered at this site. Prior to the start of the piling works, the ground level was reduced from the street level to approximately $8 \mathrm{mOD}$ (metres above Ordnance Datum). During excavation, the groundwater table was found to lie on average at about $5 \mathrm{~m}$ below the piling platform - that is, at about $3 \mathrm{mOD}$.

\begin{tabular}{ll}
$\begin{array}{l}\text { Depth: } \mathrm{m}, \\
\text { below ground } \\
\text { level }^{\mathrm{a}}\end{array}$ & Soil description \\
\hline $0-3$ & $\begin{array}{l}\text { Made ground: concrete and tarmac surface } \\
\text { underlain by brick, ash fill and sandstone } \\
\text { fragments }\end{array}$ \\
$3-5$ & $\begin{array}{l}\text { Firm brown silty clay and loose sand (alluvium) } \\
5-22\end{array}$ \\
$\begin{array}{l}\text { Medium dense becoming dense reddish } \\
\text { brown silty sand (alluvium) }\end{array}$ \\
$22-23$ to $>30$ & $\begin{array}{l}\text { Coal and sandstone } \\
\text { Bedrock: mudstone and sandstone }\end{array}$
\end{tabular}

a Piling platform level was about $4 \mathrm{~m}$ below the original ground (street) level.

Table 1. Summary of soil layers and their descriptions

However, owing to the close proximity of the site to the River Clyde, the groundwater table at the site was believed to be tidal. Although no groundwater monitoring work was conducted for this project, the nearby tidal gauge showed a daily fluctuation of about $4 \mathrm{~m}$ between high and low tides, so the groundwater level at the site should also fluctuate, although probably to a lesser extent.

Figure 1 shows an overview of the site during construction. This was a very small urban site measuring just $24 \mathrm{~m} \times 40 \mathrm{~m}$ and requiring 62 bored piles of $750 \mathrm{~mm}$ diameter to support the proposed development - that is, an average pile spacing of $4 \mathrm{~m}$. The piles were 19.5 to $23.5 \mathrm{~m}$ deep and were all socketed into the bedrock - the socket lengths ranged from 0.5 to $4.0 \mathrm{~m}$ depending on the design working load at the particular location. The requirement for a clean pile base at this site was particularly important as the piles were designed assuming an ultimate base

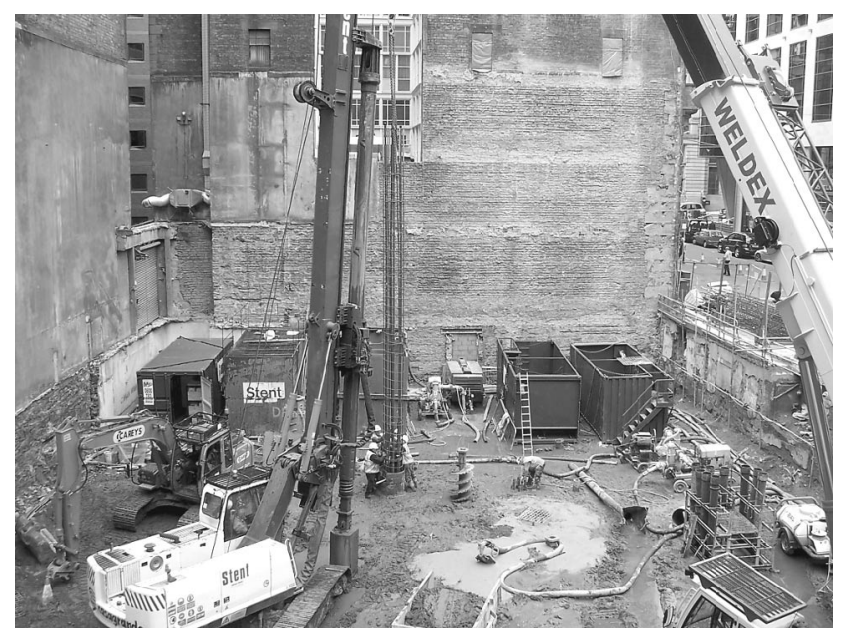

Figure 1. An overview of the urban site in central Glasgow 
stress of $6.7 \mathrm{MPa}$ for a socket in mudstone, so that the contribution of the base resistance could be up to $50 \%$ for piles with a short socket. As for other sites in central Glasgow, bored piling utilising polymer fluids was the preferred method of construction because these fluids do not require bulky ancillary plant for cleaning or considerable storage space for the full-length casing option. It is for this reason that polymer fluids have been favoured over bentonite slurry for piling projects in central Glasgow over recent years. Continuous flight auger (CFA) piles were also a possible option, but in the past flighting has occurred in the loose granular deposits resulting, on occasions, in building damage (Lennon et al., 2006; Lynch, 1992). CFA piles are therefore only used in low-risk situations.

Figure 2 shows the particle-size distribution curve of the alluvial sand collected from the site. As can be seen, the sand consists of about $2 \%$ clay, $13 \%$ silt and $85 \%$ sand-sized particles, and the $D_{10}, D_{30}, D_{60}$ are 50,83 and $120 \mu \mathrm{m}$ respectively. From these, the coefficient of uniformity $\left(C_{\mathrm{U}}\right)$ and the coefficient of curvature $\left(C_{Z}\right)$ have been computed as 1.45 and 1.15 respectively, indicating a poorly graded uniform sand (classification: $\mathrm{SPu}$ ). The water content of the sand below the groundwater table was about $30 \%$, and the specific gravity of the soil grains was 2.66 as measured in accordance with BS 1377 (BSI, 1990). The saturated bulk unit weight of the material was $19 \mathrm{kN} / \mathrm{m}^{3}$ calculated from the moisture content. The angle of shearing resistance ranges from $34^{\circ}$ to $36^{\circ}$ for the medium dense becoming very dense sand at this site.

\section{Construction details}

\subsection{Polymer fluids: basic information and preparation} The polymer fluid used for this project was the 'SlurryPro CDP' system supplied by KB International. This polymer system consists of a granular base polymer called 'CDP' and a range of additives for mix water treatment, fluid cleaning, fluid loss control, fluid weighting, etc. The CDP system has been used for

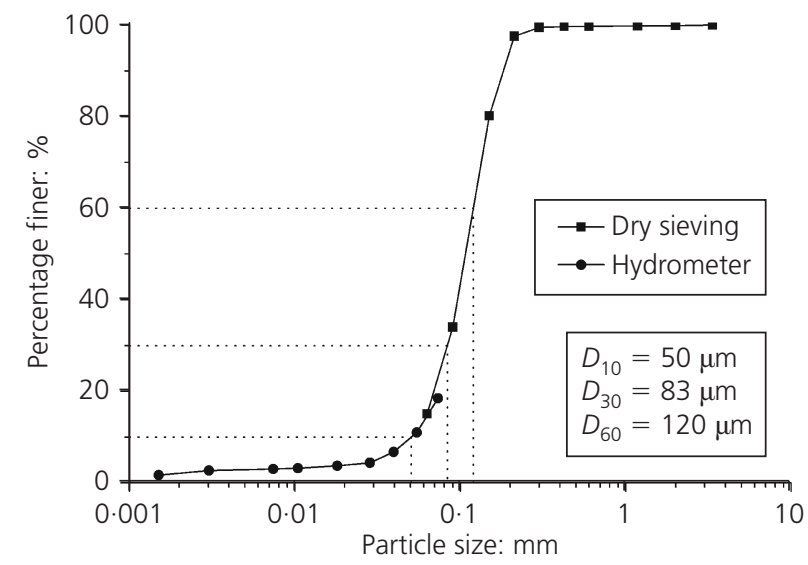

Figure 2. Particle-size distribution curve for the Glasgow silty fine sand piling projects in the UK since the late 1990s. The contractor's previous experience with this polymer system can be found in Lam et al. (2010a) and Lennon et al. (2006). Detailed chemical information can also be found in Goodhue and Holmes (1995).

To prepare the polymer fluids, the mix water was first treated with a small amount of the additive 'Protek' (potassium hydroxide) to increase the $\mathrm{pH}$ to 11 . The base polymer CDP was then added to the mixing tank to achieve a concentration of about $0.9 \mathrm{~kg} / \mathrm{m}^{3}$. To prevent clumping of the polymer granules and to promote dissolution, the mix water was agitated with a compressed air lance during polymer addition and for at least $60 \mathrm{~min}$ afterwards. Immediately after mixing, the Marsh funnel viscosity of the fluid was about $100 \mathrm{~s}$, but by the following day the viscosity was found to have reduced to about $90 \mathrm{~s}$. The reduction is believed to be due to the gradual escape of some of the entrained air bubbles in the fluid, which will have had an effect on viscosity as measured with the Marsh funnel.

\subsection{Excavation technique}

The construction process started with the insertion of a $6 \mathrm{~m}$ long steel casing and removal of the soils within the casing under dry conditions. The support fluid was then introduced into the pile bore so that excavation could be continued to the required founding level. During the process, the support fluid level was maintained at about $1 \mathrm{~m}$ below the piling platform level to counterbalance the groundwater pressure and also to exert a net stabilising pressure onto the side walls. This required about 8 to $9 \mathrm{~m}^{3}$ of support fluid for each pile. As the amount of fluid loss into the ground was not significant (about $0.5 \mathrm{~m}^{3}$ over a $12 \mathrm{~h}$ period in a $20 \mathrm{~m}$ deep completed bore) and the pile bores were generally stable, no additives were required and only occasional top-up of the support fluid was necessary.

To minimise unnecessary soil disturbance, a twin-flight piling auger and a flat-sided cleaning bucket were used for the excavation. Both tools allow fluid passage during insertion into and retrieval from the pile bore, thus preventing any sudden pressure changes in the support fluid and in the adjacent soil pore water. Figure 3 shows the twin-flight auger immediately after retrieval from a pile bore.

\subsection{Polymer fluid: test procedures and properties after excavation}

Immediately after reaching the desired founding level, used fluid samples were taken from the pile bores at three different levels: top $(2 \mathrm{~m})$, middle $(10 \mathrm{~m})$ and bottom $(18 \mathrm{~m})$. Three types of test were conducted on the fluids, namely density, sand content and the Marsh funnel viscosity. For the density measurements, a portable density meter (model DMA 35N, Anton Paar Ltd, Hertford, UK) with a resolution of $0.0001 \mathrm{~g} / \mathrm{cm}^{3}$ was used, as the resolution of the conventional mud balance $(0.01 \mathrm{~g} /$ $\mathrm{cm}^{3}$ ) was considered too low - a view also expressed in Federation of Piling Specialists (2006a). The test methods for the sand content and Marsh funnel viscosity tests followed the 


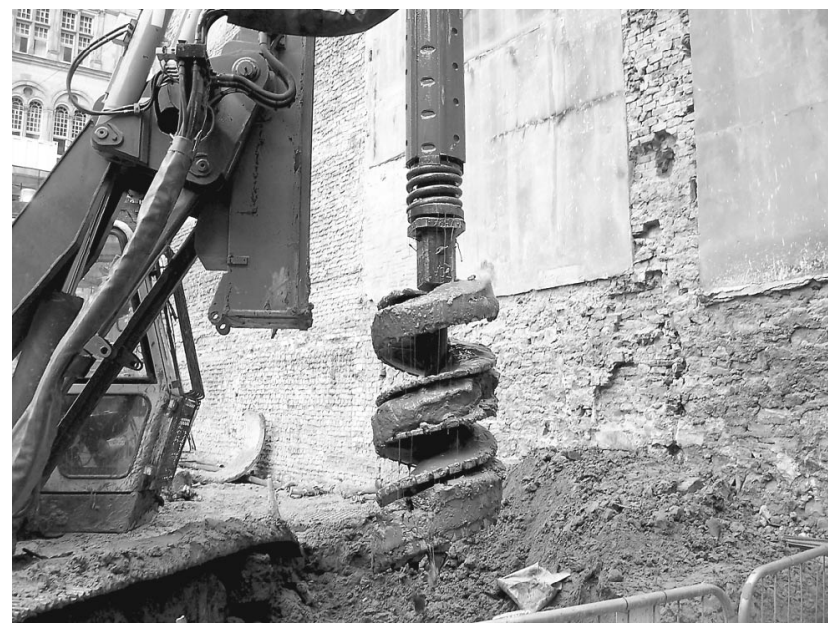

Figure 3. A twin-flight piling auger immediately after retrieval from a polymer-supported bore. Note the second flight is for fluid passage

procedures in the American Petroleum Institute (2003) and Federation of Piling Specialists (2006a) for bentonite, except that bleach was used to break the polymer prior to the sand content test. It should be noted that the sand content test was developed in the USA and the screen size is $75 \mu \mathrm{m}$. Thus the sand content test determines the quantity of material coarser than $75 \mu \mathrm{m}$ (by bulk volume).

Before each test, the fluid sample was stirred vigorously to ensure uniform dispersion of all the soil particles - a step which is especially important for the density and sand content tests. No screening was carried out to remove the coarse particles except for the Marsh funnel test where the fluid was poured through the No. 12 mesh (1.6 mm opening) built into the top of the funnel this is to prevent the gravel-sized particles from blocking the orifice which has an inside diameter of $4.7 \mathrm{~mm}$ (3/16 in). At this site, although the alluvial silty sand does not contain any gravelsized particles (Figure 2), the thin coal (lignite) layer above the bedrock was broken into small pieces of sand- and gravel-sized fragments by the excavation tools and some of them were found in suspension in the support fluids; hence the need for prescreening before the Marsh funnel tests.

Figure 4 shows the density, sand content and Marsh funnel test results plotted against depth for one of the working piles for three stages: (a) immediately after excavation, $(b)$ after fluid cleaning with the chemical additive 'MPA' and 30 min of waiting, and (c) as $(b)$ but plus an overnight waiting period. The additive 'MPA' is
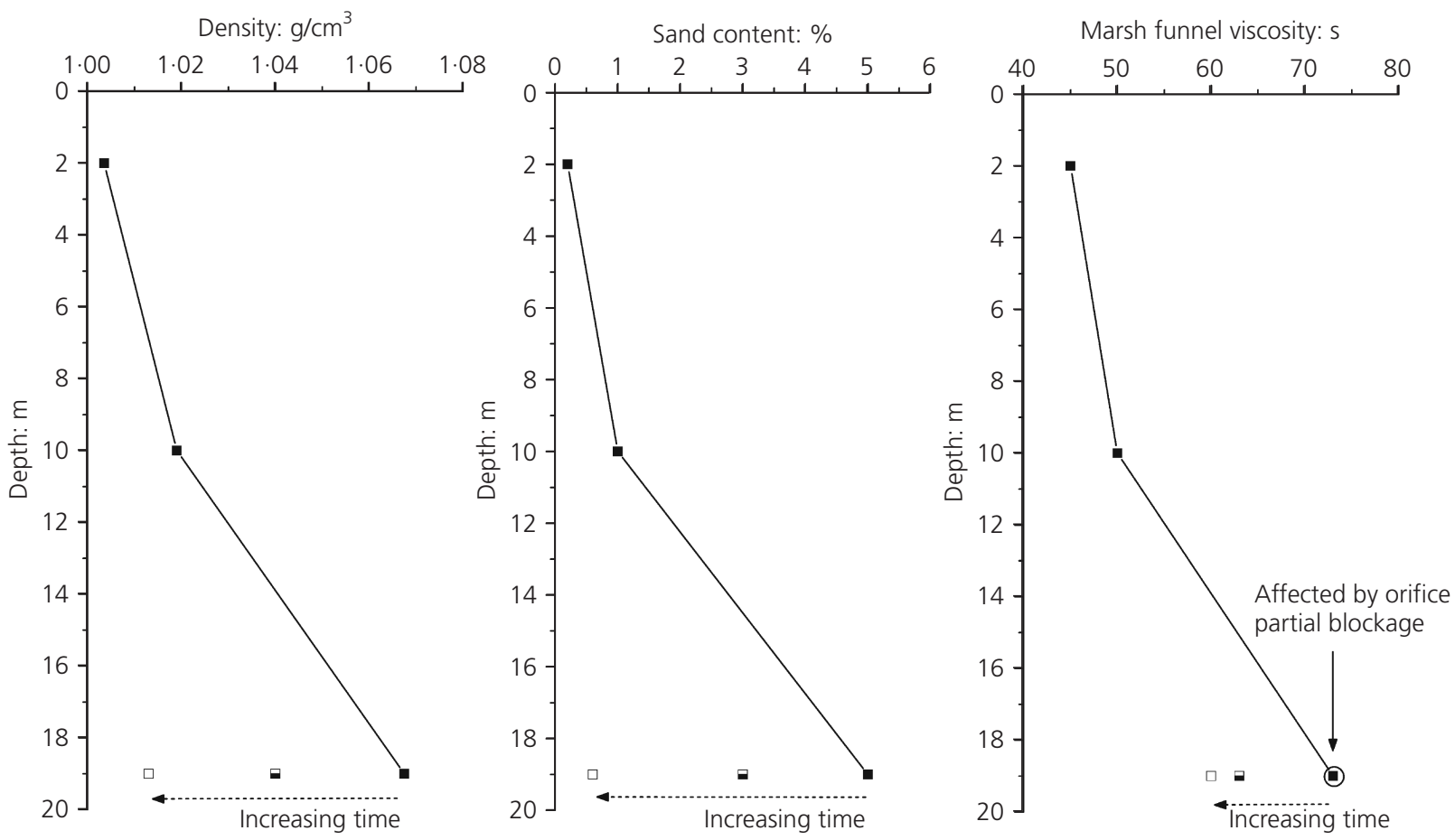

$\square$ After an additional overnight $=$ After fluid cleaning with additive - - - Immediately after excavation
waiting period

Figure 4. Density, sand content and Marsh funnel viscosity

profiles in a completed pile bore 
a proprietary chemical which is known to have a cationic charge and will interact with the base polymer 'CDP'. It can be seen from the plots that all three measured parameters show an increasing trend with depth. This indicates that the suspended soil particles were settling in the pile bores at the time of sampling. Even though care was taken to prevent the coarse particles from blocking the orifice of the Marsh funnel by pre-screening the test fluids, some accumulated sand and silt particles were found near the bottom of the funnel at the end of the viscosity test conducted on the fluid sample that was taken from the base of the pile bore. The settled particles were found to have slightly reduced the internal diameter of the orifice and possibly affected the viscosity results. The corresponding viscosity data point is pointed out in Figure 4.

\subsection{Fluid cleaning by the use of additives}

As the test results showed that the support fluid was heavily laden with solids, it was necessary either to clean the fluid using additives or to exchange it for fresh fluid (as is done for piles under bentonite). The additive used was MPA, which was supplied as a viscous concentrated solution. The fluid-cleaning procedure involved dropping a weighted package (colloquially known as a 'bomb') containing 5-10 litres of 1\% diluted MPA solution to the base of the pile bore. The package was broken by rotating a cleaning bucket and the contents were dispersed by gently raising and lowering the bucket a few times over a height of $3-5 \mathrm{~m}$ from the base of the excavation. A $30 \mathrm{~min}$ waiting period then followed to allow the additive to coagulate the suspended particles and to allow the collected solids to settle to the base of the bore. Figure 5 shows the coagulated gel mass formed by adding MPA to a bucket of used CDP fluid heavily laden with soil. It should be noted that in this bucket demonstration, undiluted MPA solution was used so that the effect was more dramatic than would be expected in a pile bore, for which $1 \%$ (one hundred times) dilution is recommended by the supplier.

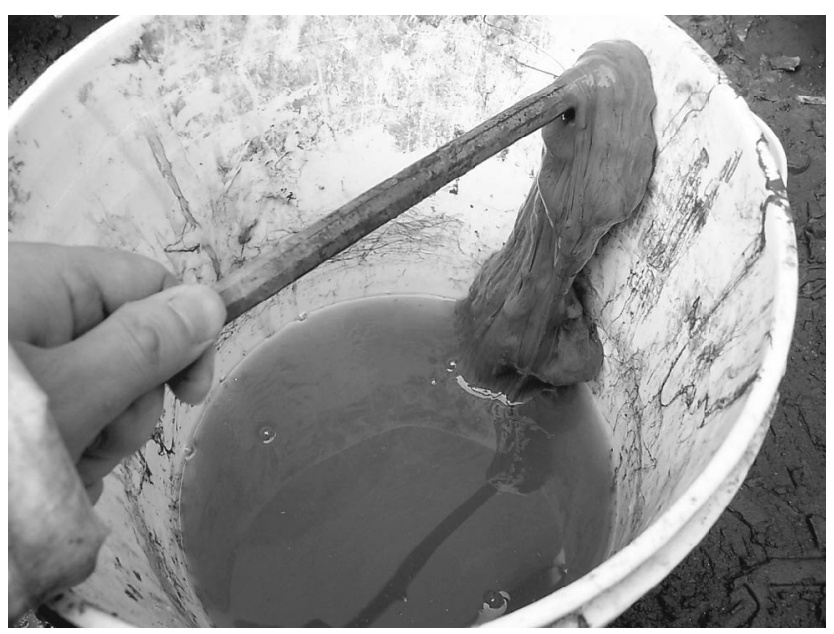

Figure 5. Coagulated gel mass formed after adding cleaning additives into a bucket of used fluid on site
After the 30 min waiting period, a further fluid sample was taken from the bottom of the bore to measure the effect on fluid properties. The results are shown in Figure 4 and it can be seen that all three parameters showed a reduction as a result of the reduced suspended solid concentration. However, the values still exceeded the allowable upper limits in the project specifications $\left(<1 \%\right.$ sand content and $<1.02 \mathrm{~g} / \mathrm{cm}^{3}$ density), despite previous success of following the same procedure at a predominantly clay site in London (Lam et al., 2010a). These tests suggested that fluid cleaning with additives alone was not sufficient for the soil conditions at the site and that either a complete fluid exchange or further cleaning was required to eliminate the risks of 'soft toe' and concrete contamination.

\subsection{Fluid cleaning by further waiting}

To reduce the amount of suspended soil particles further, it was decided to leave the pile bore open overnight to give the particles extra time to settle out of suspension. In this regard, the pile bore was used as a sedimentation 'tank' to allow the support fluid to self-clean - an option available in the polymers but not bentonite. After the further waiting period, another fluid sample was taken from the bottom of the pile bore and tested for the same parameters as before. The results are also shown in Figure 4. It can be seen that the values of all the three parameters had been further reduced to within the upper limits for sand content and density.

\subsection{Sediment build-up during the waiting periods}

To shed light on the sediment formation behaviour in the pile bore, during the waiting periods the depth of the bore was also checked regularly by a weighted measuring tape. Although the accuracy of this measurement method is rather low $( \pm 50 \mathrm{~mm}$ approx.), an interesting pattern was revealed which is shown in Figure 6. It can be seen that as soon as the excavation was completed, sediment started to accumulate at the pile base and continued throughout the waiting periods. All the sediment was removed by a cleaning bucket at the end and hence the thickness

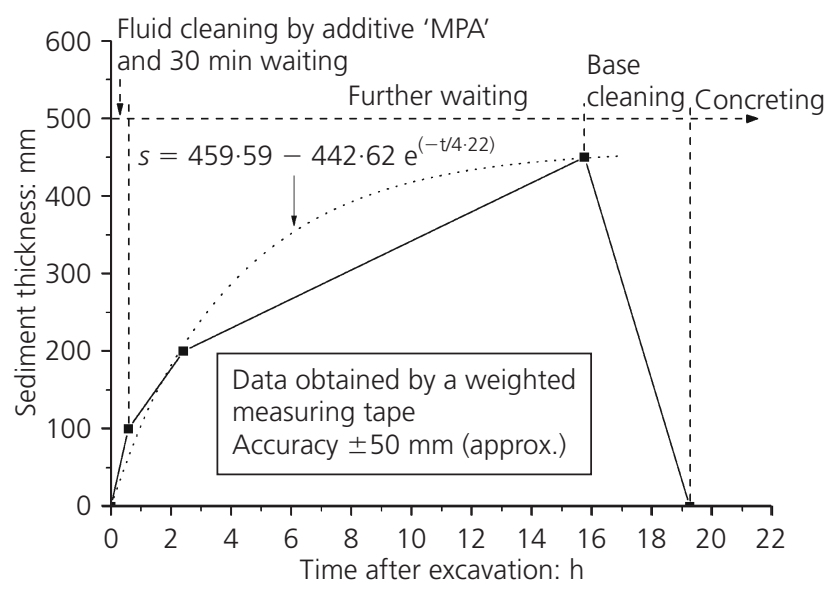

Figure 6. Sediment build-up at the base of a completed pile bore 
was reduced to zero prior to concreting. The results of the depth measurements also indirectly show that the side wall did not collapse during the waiting periods, or had a collapse occurred the sediment depth would have suddenly increased. A simple decay function has also been fitted to the data points to simulate the build-up of sediment thickness $(s)$ over time $(t)$. It is predicted that after $16 \mathrm{~h}$ the sedimentation process was almost complete, suggesting that further waiting would not bring extra benefits. Of course, for other sites the sediment build-up characteristics would be different depending on the ground conditions, fluid properties immediately after excavation and the depth of the excavation.

\subsection{Concreting}

To avoid intermixing of the wet concrete and the support fluid, the piles were concreted using a tremie pipe which had diameter of $150 \mathrm{~mm}$. The hopper and the tremie pipe sections used are shown on the right-hand side of Figure 1. A vermiculite plug was used to separate the first pour of concrete and the support fluid. During concreting, the tremie pipe was lifted as the concrete level rose in order to maintain an embedment depth of between 3 and $6 \mathrm{~m}$. Owing to the fluid-cleaning work described above, the concrete at the top of the concrete column appeared clean, although a small degree of intermixing was observed as shown in Figure 7. A small amount (approximately $0 \cdot 2 \mathrm{~m}^{3}$ ) of overpouring was therefore necessary to ensure the quality of concrete at the pile top.

\section{Structural integrity and dynamic load tests}

To confirm the structural integrity of the completed piles, they were tested by the low-strain pulse-echo method ( 55 piles) and

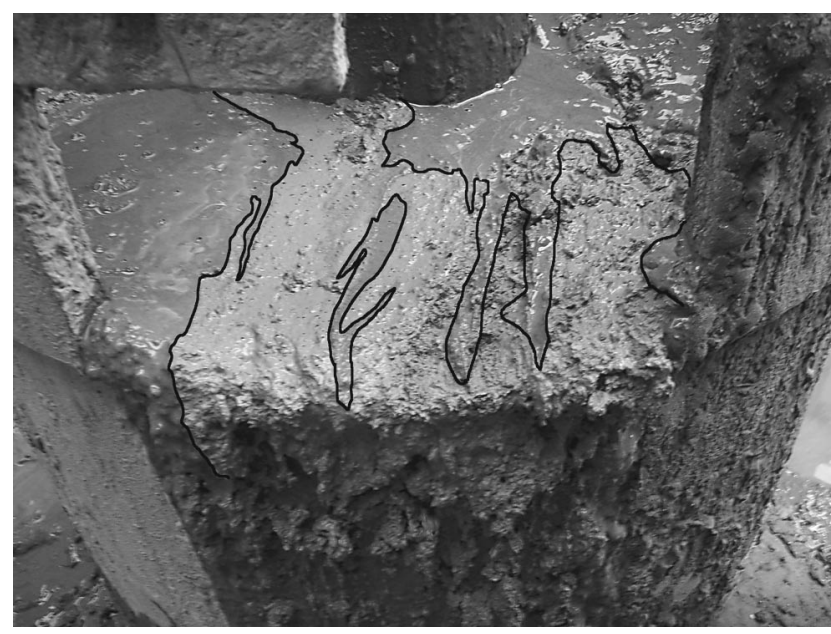

Figure 7. Fresh concrete as it first appeared at the top of a polymer-supported bore during tremie concreting. The boundaries between the fresh concrete and polymer fluids have been highlighted in black. Dark shade: used polymer fluid. Light shade: fresh concrete ultrasonic cross-hole logging (four piles). A specialist subcontractor was employed to conduct this work about 3-4 weeks after construction. Descriptions of the test procedures can be found in manuals such as Federation of Piling Specialists (2006b) and Turner (1997), so they are not repeated here. From the tests, none of the piles tested was found to show any sign of defects or integrity problems (inclusions, necking etc.). Figure 8 shows a typical cross-hole ultrasonic trace for one of the piles. The traces on the left-hand side show the first arrival time (FAT) and relative energy (dimensionless) traces with depth. The right-hand traces show the full sonic profile with time - the positive part of the waveform is shown light and the negative portion is shown dark. It can be seen that the pile has uniform FAT and energy profiles over the entire length of the sonic tubes, suggesting that the pile material is of sound and uniform quality. Concrete containing inhomogeneities, such as soil inclusions, wash-out and pockets of support fluids, would show localised lower arrival times and attenuated signals. It is interesting to compare the present authors' structural integrity findings with those of Amir (2007) who showed a significant defect in a bored pile constructed under polymer fluid. The authors believe that the defect shown in Amir (2007) was probably caused by factors other than the use of polymer fluids.

To confirm that the piles constructed will also perform satisfactorily under the design working loads, two of the piles were tested by the high-strain dynamic method about a month after construction. No static load tests were performed. The dynamic tests involved dropping a $3.5 \mathrm{t}$ hammer from a height of between 800 and $1300 \mathrm{~mm}$ onto the pile head. The pile strain and acceleration were measured by strain transducers and accelerometers placed on the two opposite faces of the shaft about two pile diameters below the pile head. The data collected were analysed using the CAse Pile Wave Analysis Program (CAPWAP ${ }^{\circledR}$ ) signal-matching technique to estimate the mobilised shaft and toe resistances and also the likely immediate settlement under static loads. During the analyses, soil parameters were adjusted until a good match was obtained between the measured and simulated response. Table 2 summarises the test pile information and the CAPWAP results. It can be seen that both piles had mobilised total resistances considerably greater than the working loads and that the predicted pile head settlements under the working loads were small. As both piles only settled by about $1 \mathrm{~mm}$ per blow (5$6 \mathrm{~mm}$ per five blows), the total resistance values given in Table 2 are likely to be considerably smaller than the 'true' ultimate resistance, which typically requires a minimum of $2-3 \mathrm{~mm}$ set per blow to mobilise during the test. Overall, the results show that the quality of the completed piles was entirely satisfactory both structurally and geotechnically.

\section{Conclusion}

A case history in Glasgow has been presented to illustrate how the common problems of 'soft toe' and concrete contamination can be avoided at sites with silty fine sand - a soil type that has been found problematic for polymer fluids. The improved 


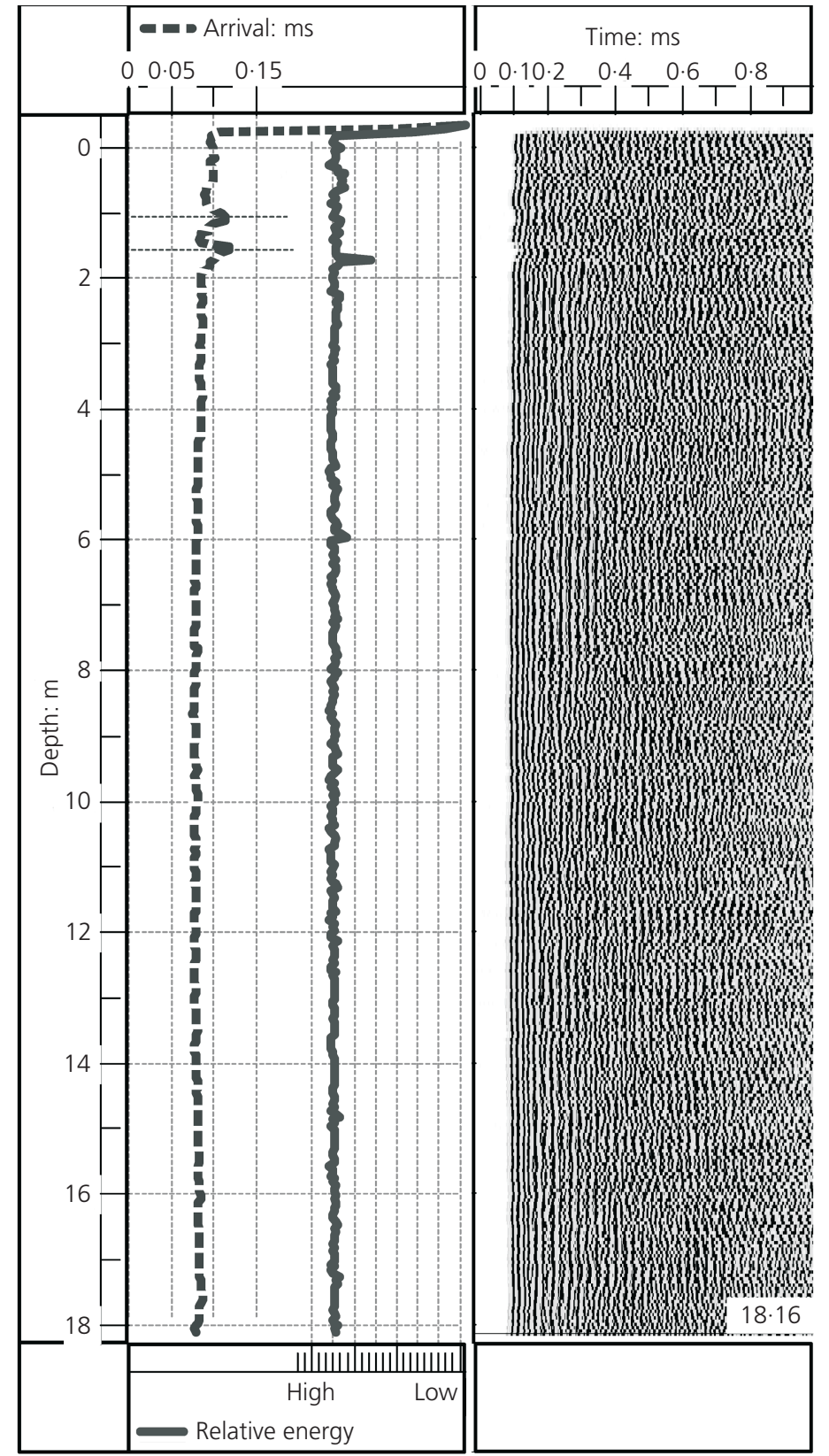

Figure 8. Typical cross-hole ultrasonic logging profiles for piles constructed using polymer fluids coupled with fluid cleaning and overnight waiting

construction procedures have been discussed, and it has been shown that the completed bored piles are of good quality both structurally and geotechnically. The key findings from the site work may be summarised as follows.

(a) For the soil conditions at the site in Glasgow, testing conducted at the end of excavation showed that the support fluid was heavily laden with soil solids. The use of chemical additives alone was found to be insufficient to remove the suspended particles within a $30 \mathrm{~min}$ period and a further overnight waiting period was required for the density and sand content values to fall below prescribed limits. A complete fluid exchange would have achieved a similar result but would have required extra fluid operations.

(b) Depth checking in one of the pile bores showed that sediment started accumulating at the pile base immediately after excavation and continued throughout the $16 \mathrm{~h}$ waiting period. This shows the importance of adopting a sediment management and removal procedure without which a 'soft toe' would have developed during insertion of the reinforcing 
steel cage and build-up of tremie pipes. The fresh concrete also would have been contaminated by the settling soil particles during casting, as reported in other case histories. Depth (sediment thickness) measurements such as those shown in Figure 6 can be carried out by engineers at other construction sites to reveal the rate of particle sedimentation. The results then can be used to determine the time required for self-cleaning of the fluid in pile bores.

(c) Low-strain pile integrity tests and cross-hole ultrasonic logging confirmed that the completed piles are of sound quality without any sign of defects or integrity problems. This is in contrast to the finding of Amir (2007), who reported a significant defect in a bored pile constructed using a polymer fluid. High-strain dynamic load tests showed that the piles all performed to the design requirements, despite the additional overnight waiting period; similar findings were also reported by Wheeler (2003) and Lam et al. (2010a) for two different London sites.

(d) In addition to preventing the formation of 'soft toe' and concrete contamination, allowing pile bores to be left open overnight allows the piling contractor to improve efficiency and productivity, as work can be sequenced more flexibly with less standing time for the workforce and plant.

\section{Acknowledgements}

The data presented in this paper were collected as part of a research project jointly funded by the UK Engineering and Physical Sciences Research Council (EPSRC), Balfour Beatty Ground Engineering (BBGE) and KB International LLC; grant reference No. EP/C537815/1. Additional financial support was provided by the ICE R\&D Enabling Fund (reference No. 1102). The authors would like to thank Messrs Allan Bowers and Viv Troughton (both formerly BBGE) who provided technical support to the project described in this paper and Dr William H. Craig who reviewed the first draft of this paper. The comments of the members are also gratefully acknowledged.

\section{REFERENCES}

American Petroleum Institute (2003) API RP 13B-1:

Recommended practice for field testing water-based drilling fluids, 3rd edn. API, Washington, DC, USA.

Amir JM (2007) Discussion of 'Reliability evaluation of crosshole sonic logging for bored pile integrity'. Journal of Geotechnical and Geoenvironmental Engineering 133(3): $342-343$.

Anonymous (2001) Way out of a tight spot. Ground Engineering 34(5): $16-17$.

Brown DA (2004) Zen and the art of drilled shaft construction: the pursuit of quality. In Proceedings of GeoSupport 2004 Conference, Orlando (Turner JP and Wayne PW (eds)). American Society of Civil Engineers, Reston, VA, USA, pp. 19-33, Geotechnical Special Publication No. 124.

BSI (1990) BS 1377-2:1990. Methods of test for soils for civil engineering purposes. Classification tests. BSI, London, UK. 
Federation of Piling Specialists (2006a) Bentonite Support Fluids in Civil Engineering, 2nd edn. FPS, Kent, UK.

Federation of Piling Specialists (2006b) Handbook on Pile Load Testing. FPS, Kent, UK.

Fleming K, Weltman A, Randolph M and Elson K (2009) Piling Engineering, 3rd edn. Taylor \& Francis, Abingdon, UK.

Goodhue KG Jr and Holmes MM (1995) Earth Support Fluid Composition and Method for Its Use. United States Patent 5 407 909, April.

Jefferis SA and Lam C (2013) Polymer support fluids: use and misuse of innovative fluids in geotechnical works.

Proceedings of the 18th International Conference on Soil Mechanics and Geotechnical Engineering, Paris. Presses des Ponts, Paris, vol. 4, pp. 3219-3222.

Lam C, Troughton V, Jefferis S and Suckling T (2010a) Effect of support fluids on pile performance - a field trial in east London. Ground Engineering 43(10): 28-31.

Lam C, Jefferis SA and Goodhue KG Jr (2010b) Observations on viscosity reduction of PHPA polymer support fluids. In Proceedings of Sessions of the GeoShanghai 2010 International Conference, Shanghai (Liang RY, Zhang F and Yang K (eds)). American Society of Civil Engineers, Reston, VA, USA, pp. 184-191, Geotechnical Special Publication No. 205.
Lam C, Jefferis SA and Martin CM (2014a) Effects of polymer and bentonite support fluids on concrete-sand interface shear strength. Géotechnique 64(1): 28-39.

Lam C, Martin PJ, Jefferis SA and Goodhue KG Jr (2014b) Determination of residual concentration of active polymer in a polymeric support fluid. Geotechnical Testing Journal 37(1): 46-59.

Lennon DJ, Ritchie D, Parry GO and Suckling TP (2006) Piling projects constructed with vinyl polymer support fluid in Glasgow, Scotland. Proceedings of the 10th International Conference on Piling and Deep Foundations, Amsterdam. Deep Foundations Institute, Hawthorne, NJ, USA, pp. 499506.

Lynch PJ (1992) Partial displacement pile system for urban sites. In Piling: European Practice and Worldwide Trends (Sands MJ (ed.)). Thomas Telford, London, UK, pp. 254261.

Schünmann D (2004) Fisherman's friend. Ground Engineering 37(12): 17.

Turner MJ (1997) Integrity Testing in Piling Practice. Construction Industry Research and Information Association, London, UK, Ciria Report 144.

Wheeler P (2003) Piles unlock polymer potential. Ground Engineering 36(SUPP): 8-9.

\section{WHAT DO YOU THINK?}

To discuss this paper, please email up to 500 words to the editor at journals@ice.org.uk. Your contribution will be forwarded to the author(s) for a reply and, if considered appropriate by the editorial panel, will be published as a discussion in a future issue of the journal.

Proceedings journals rely entirely on contributions sent in by civil engineering professionals, academics and students. Papers should be 2000-5000 words long (briefing papers should be 1000-2000 words long), with adequate illustrations and references. You can submit your paper online via www.icevirtuallibrary.com/content/journals, where you will also find detailed author guidelines. 